\title{
Low-Voltage, Flexible InGaZnO Thin-Film Transistors Gated with Solution-Processed, Ultra-Thin AlxOy
}

DOI:

10.1109/LED.2018.2882464

\section{Document Version}

Accepted author manuscript

Link to publication record in Manchester Research Explorer

\section{Citation for published version (APA):}

Cai, W., Wilson, J., Zhang, J., Park, S., Majewski, L., \& Song, A. (2019). Low-Voltage, Flexible InGaZnO Thin-Film Transistors Gated with Solution-Processed, Ultra-Thin AlxOy. IEEE Electron Device Letters, 40(1), 36-39. https://doi.org/10.1109/LED.2018.2882464

\section{Published in:}

IEEE Electron Device Letters

\section{Citing this paper}

Please note that where the full-text provided on Manchester Research Explorer is the Author Accepted Manuscript or Proof version this may differ from the final Published version. If citing, it is advised that you check and use the publisher's definitive version.

\section{General rights}

Copyright and moral rights for the publications made accessible in the Research Explorer are retained by the authors and/or other copyright owners and it is a condition of accessing publications that users recognise and abide by the legal requirements associated with these rights.

\section{Takedown policy}

If you believe that this document breaches copyright please refer to the University of Manchester's Takedown Procedures [http://man.ac.uk/04Y6Bo] or contact uml.scholarlycommunications@manchester.ac.uk providing relevant details, so we can investigate your claim.

\section{OPEN ACCESS}




\title{
Low-Voltage, Flexible InGaZnO Thin-Film Transistors Gated with Solution-Processed, Ultra-Thin $\mathrm{Al}_{\mathrm{x}} \mathrm{O}_{\mathrm{y}}$
}

\author{
Wensi Cai, Joshua Wilson, Jiawei Zhang, Seonghyun Park, Leszek Majewski, Senior member, IEEE, \\ and Aimin Song, Senior member, IEEE
}

\begin{abstract}
Indium-gallium-zinc-oxide thin-film transistors (TFTs) gated with solution-processed, ultra-thin $\mathrm{Al}_{\mathrm{x}} \mathrm{O}_{\mathrm{y}}$ have been fabricated on a plastic substrate. The effects of bending on the gate dielectric in terms of leakage current density and capacitance density have been studied. The devices show a low operating voltage of less than $1 \mathrm{~V}$, a high current on/off ratio $>10^{5}$ and a low subthreshold swing $<90 \mathrm{mV} / \mathrm{dec}$. The devices maintain their high performance even when flexed to a curvature radius of $11 \mathrm{~mm}$. As a result, such devices possess a great potential for low-power, flexible electronics.
\end{abstract}

Index Terms- Indium-gallium-zinc-oxide, thin-film transistors (TFTs), plastic substrate, $1 \mathrm{~V}$ operation

\section{INTRODUCTION}

$\mathrm{I}^{\mathrm{n}}$ n recent years, thin-film transistors (TFTs) based on oxidesemiconductors, especially indium-gallium-zinc-oxide (IGZO), have shown great potential in a wide range of electronic applications, such as displays and radio frequency identification (RFID), due to their excellent mobility, transparency, flexibility and large-area uniformity [1]. Many next generation electronic devices will require reduced power consumption, hence it is highly desirable for TFTs to be capable of low-voltage operation. However, it is still challenging for oxide-semiconductor-based TFTs to achieve both high current on/off ratios and low operating voltages at same time.

Operating voltages can be reduced by increasing the capacitance of gate dielectric materials. One method is to reduce the insulator thickness. However, for traditional insulators like $\mathrm{SiO}_{2}$, such a method may result in a large gate leakage current if the insulator layer is too thin [2]. To increase the gate capacitance without dramatically increasing the gate leakage current, high dielectric constant (high- $\kappa$ ) materials, such as $\mathrm{Al}_{2} \mathrm{O}_{3}, \mathrm{HfO}_{2}$ and $\mathrm{Ta}_{2} \mathrm{O}_{5}$, can be used as the

This paragraph of the first footnote will contain the date on which you submitted your paper for review. This work was supported by the Engineering and Physical Sciences Research Council (EPSRC) (Grant No. EP/N021258/1), North-West Nanoscience Doctoral Training Centre, EPSRC (Grant No. EP/G03737X/1), UMIP Proof of Principle project, National Key Research and Development Program of China (Grant No. 2016YFA0301200), National Natural Science Foundation of China (Grant Nos. 11374185 and 11304180).

W. Cai, J. Wilson, J. Zhang, S. Park, L. Majewski and A. Song are with School of Electrical and Electronic Engineering, The University of Manchester, Manchester M13 9PL, UK (email: A.song@manchester.ac.uk). gate dielectric layer [3-5]. A widely-used high- $\kappa$ material is $\mathrm{Al}_{2} \mathrm{O}_{3}$, due to its large bandgap, low cost, low leakage current density and good compatibility with oxide semiconductors [3].

Commonly, pinhole free aluminum oxide is deposited using atomic layer deposition (ALD) [6]. However, ALD normally suffers from a slow growth rate and it is still challenging to use ALD for large-area, non-vacuum deposition. Alternatively, high-quality aluminum oxide can be deposited using anodization, which has been proven to be a costefficient technique for large-area, room temperature fabrication of capacitors [7]. Anodization is a self-limiting process, meaning pinhole free, homogeneous oxides can be created, even at an ultra-thin thickness [8]. The low deposition temperature also makes it compatible with flexible substrates. We have recently shown that using anodized, ultra-thin $\mathrm{Al}_{\mathrm{x}} \mathrm{O}_{\mathrm{y}}$ as the gate dielectric layer, it is possible to fabricate IGZO TFTs with an ultra-low operating voltage of $1 \mathrm{~V}$ [9]. However, these devices were fabricated on a rigid glass substrate.

Here, IGZO TFTs with solution-processed, ultra-thin $\mathrm{Al}_{\mathrm{x}} \mathrm{O}_{\mathrm{y}}$ as gate dielectrics have been fabricated on polyethylene naphthalate (PEN) substrates. The fabricated devices operate within $1 \mathrm{~V}$ with a high current on/off ratio $>10^{5}$ and a low subthreshold swing $<90 \mathrm{mV} / \mathrm{dec}$. The devices maintain their high performance even when flexed to a curvature radius of $11 \mathrm{~mm}$.

\section{EXPERIMENTAL PROCEDURE}

Flexible IGZO-based TFTs with a bottom gate, top contact structure were fabricated on PEN substrates. A schematic of the devices is shown in Fig. 1(a). Firstly, a $200 \mathrm{~nm}$ thick polymethyl methacrylate (PMMA) layer was spin-coated onto the PEN as a buffer layer to improve the smoothness of the surface. A $200 \mathrm{~nm}$ thick layer of Al was then thermally evaporated as the gate electrode. Next, an $\mathrm{Al}_{\mathrm{x}} \mathrm{O}_{\mathrm{y}}$ layer approximately $3 \mathrm{~nm}$ thick was formed by anodization in a $1 \mathrm{mM}$ citric acid solution using the process conditions reported previously [9]. Then, a $30 \mathrm{~nm}$ thick IGZO channel layer was RF sputtered in pure argon ambient at $45 \mathrm{~W}$. After that, $200 \mathrm{~nm}$ thick $\mathrm{Al}$ source and drain were thermally evaporated through a shadow mask. The channel length and width were $60 \mu \mathrm{m}$ and $2 \mathrm{~mm}$, respectively. Finally, the devices were passivated by spin-coating a $200 \mathrm{~nm}$ thick PMMA followed with a $70{ }^{\circ} \mathrm{C}$ annealing in air ambient for 20 minutes. 


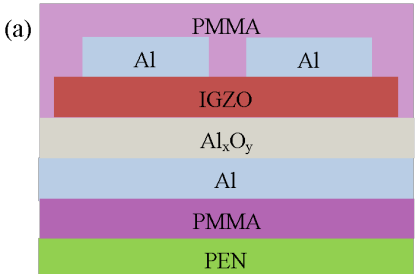

(b)

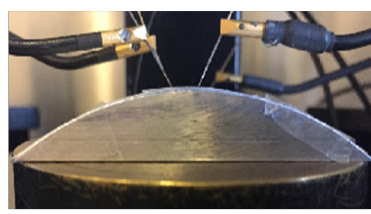

Fig. 1. (a) Schematic of IGZO TFTs on flexible PEN substrates. (b) Photo of the electrical measurement set up of the flexible IGZO TFTs bent on a curved surface with a curvature radius of $3.5 \mathrm{~cm}$.

Fig. 1(b) shows the PEN TFT array undergoing electrical measurement on a curved surface, thereby demonstrating their flexibility. The bending radius in this case is $3.5 \mathrm{~cm}$. The electrical properties of the TFTs were measured using an Agilent E5270B semiconductor analyzer and an E4980A LCR meter at room temperature.

\section{RESUlTS AND DisCUSSIONS}

Fig. 2(a) shows the capacitance density as a function of frequency $(C-f)$ of $\mathrm{Al} / \mathrm{Al}_{\mathrm{x}} \mathrm{O}_{\mathrm{y}} / \mathrm{Al}$ capacitor at a bias voltage of $1 \mathrm{~V}$ before and after bending. A very slight change of capacitance density is found in both cases, indicating low defect densities in the thin film. Fig. 2(b) shows the capacitance density as a function of applied voltage $(C-V)$ of the capacitors at $100 \mathrm{kHz}$ before and after bending. The capacitance per unit area is found to be almost the same at $900 \mathrm{nF} / \mathrm{cm}^{2}$ before and after bending.
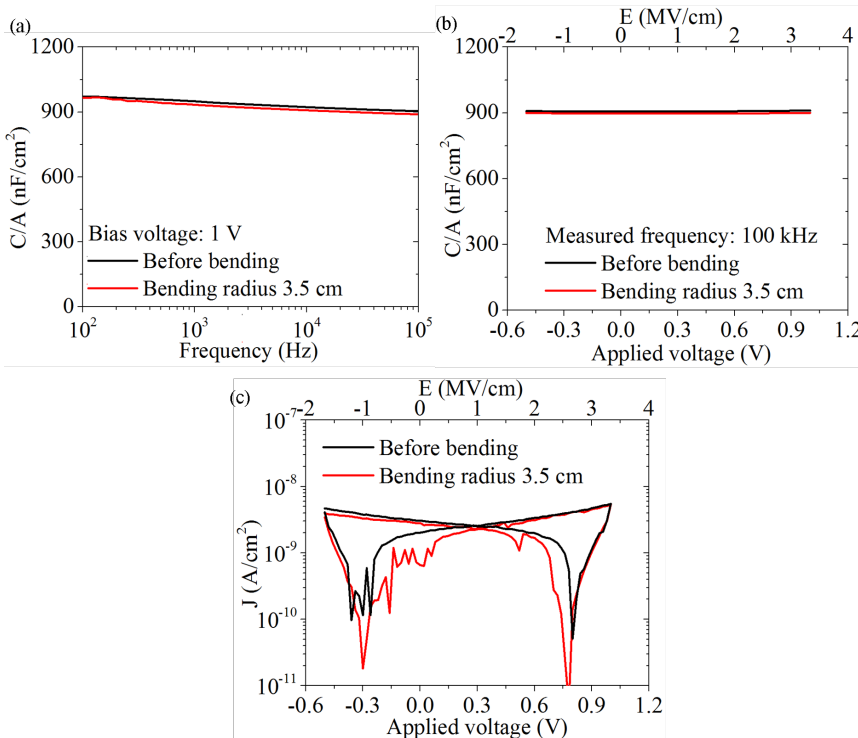

Fig. 2 (a) $C-f$, (b) $C-V$ and (c) $J-V$ characteristics of $\mathrm{Al} / \mathrm{Al}_{\mathrm{x}} \mathrm{O}_{\mathrm{y}} / \mathrm{Al}$ capacitors before and after bending. The bending radius is $3.5 \mathrm{~cm}$.

The leakage current density-voltage $(J-V)$ characteristics of the capacitors are shown in Fig. 2(c). A maximum leakage current density of $\sim 6 \mathrm{nA} / \mathrm{cm}^{2}$ is found at $1 \mathrm{~V}(3.33 \mathrm{MV} / \mathrm{cm})$, which is better than most previously reported anodized oxide layers fabricated on flexible substrates [10, 11]. Almost no leakage current density change is found after bending, demonstrating a good flexibility of the anodized, ultra-thin $\mathrm{Al}_{\mathrm{x}} \mathrm{O}_{\mathrm{y}}$. To verify the uniformity and reproducibility, 10 devices that were fabricated in different batches were randomly chosen from 35 devices to measure the capacitance and leakage current density before and after bending. The obtained results show a capacitance density of $910 \pm 30 \mathrm{nF} / \mathrm{cm}^{2}$ and a maximum leakage current density of $13 \pm 7 \mathrm{nA} / \mathrm{cm}^{2}$ with negligible change being observed after bending, confirming a high uniformity and reproducibility.

Fig. 3(a) shows the output characteristics $\left(I_{\mathrm{D}}-V_{\mathrm{D}}\right)$ of the flexible TFTs. The device operates in $n$-type enhancement mode with linear, pinch off and saturation regimes clearly shown. Fig. 3(b) shows the corresponding transfer characteristics. The current on/off ratio is found to be larger than $10^{5}$ with an almost zero hysteresis between forward $(-0.5$ to $1 \mathrm{~V}$ ) and backward (1 to $-0.5 \mathrm{~V}$ ) sweeps. The subthreshold swing, $S S$, is found to be $83 \mathrm{mV} / \mathrm{dec}$, which is close to the theoretical limit at $300 \mathrm{~K}$ [12]. A leakage current, $I_{\mathrm{G}}$, less than $1 \mathrm{nA}$ is achieved throughout the whole test, confirming the good insulating behavior of anodized, ultra-thin $\mathrm{Al}_{\mathrm{x}} \mathrm{O}_{\mathrm{y}}$. The relationship between square root of drain current, $I_{\mathrm{D}}{ }^{1 / 2}$, and gate voltage, $V_{\mathrm{G}}$, is also displayed in Fig. 3(b), from which a threshold voltage, $V_{\mathrm{TH}}$, of $0.44 \mathrm{~V}$ is extracted.
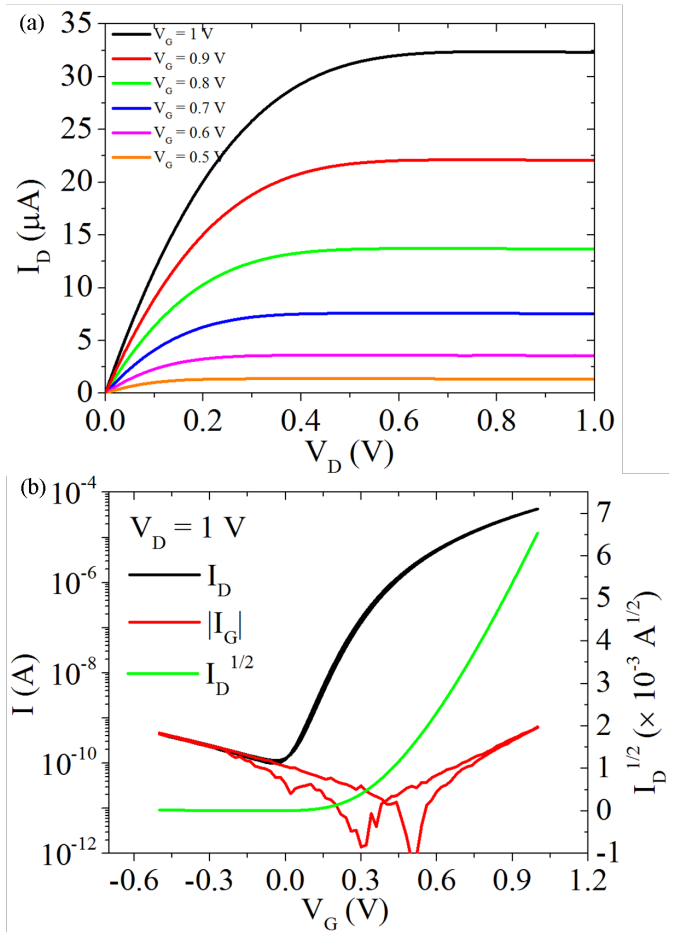

Fig. 3. Electrical properties of the flexible IGZO TFTs. (a) Output characteristics. (b) $I_{\mathrm{D}}, I_{\mathrm{D}}^{1 / 2}$ and $I_{\mathrm{G}}$ as a function of $V_{\mathrm{G}}$ at $V_{\mathrm{D}}=1 \mathrm{~V}$.

In the saturation regime $\left(V_{\mathrm{D}}>V_{\mathrm{G}}-V_{\mathrm{TH}}\right)$,

$$
I_{D}=\frac{1}{2} \frac{W}{L} \mu C\left(V_{G}-V_{T H}\right)^{2},
$$

where $W / \mathrm{L}$ is the ratio of channel width and length, $C$ is the capacitance per unit area. By taking into account the gate capacitance density $\left(900 \mathrm{nF} / \mathrm{cm}^{2}\right)$, a mobility, $\mu$, of $9 \mathrm{~cm}^{2} / \mathrm{Vs}$ can be calculated. This mobility value is an improvement upon our previous work [9] and may be ascribed to the increase of IGZO deposition power and thickness [13, 14], and the help of top capping layer $[15,16]$.

To measure flexibility, the TFTs were bent onto a curvature holder (as shown in Fig. 1(b)) with bending radius from $5 \mathrm{~cm}$ to $1.1 \mathrm{~cm}$. For each bending radius, the TFTs were bent for 20 
minutes before measuring the electrical characteristics. As shown in Fig. 4(a), there is no pronounced device performance degradation, indicating there is no obvious strain-induced cracking or buckling in the films due to bending.
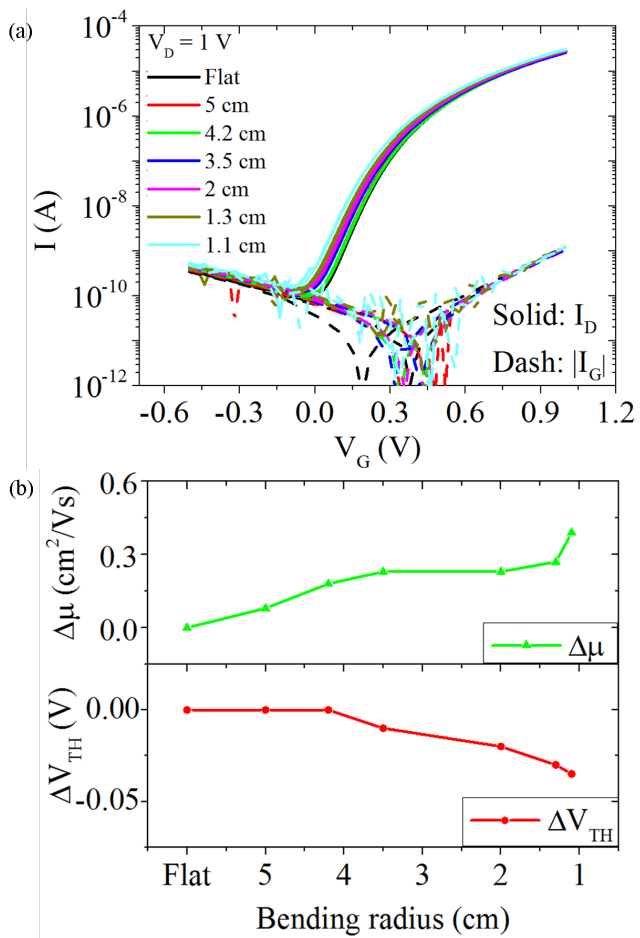

Fig. 4. (a) Transfer characteristics of flexible IGZO TFTs under various bending radii. (b) Mobility and threshold voltage change as a function of bending radius.

The corresponding mobility change $(\Delta \mu)$ and threshold voltage change $\left(\Delta V_{\mathrm{TH}}\right)$ as a function of bending radius is shown in Fig. 4(b). Under a bending radius of $11 \mathrm{~mm}$, mobility increased by $0.39 \mathrm{~cm}^{2} / \mathrm{Vs}$ and threshold voltage left shifted by $0.035 \mathrm{~V}$. A possible reason for this is the distance between atoms in the IGZO semiconductor layer increases during bending, resulting in more electrons moving to the antibonding state and therefore increasing the channel conductivity [17].

Importantly, throughout the whole test, the current on/off ratio remained $>10^{5}$ and the subthreshold swing was $<90 \mathrm{mV} / \mathrm{dec}$. These results are maintained even after several bending events. The bending test have also been carried on for several devices and all of them show a similar behavior with a left shift of threshold voltage of $0.04 \pm 0.01 \mathrm{~V}$ and an increase of mobility of $0.4 \pm 0.12 \mathrm{~cm}^{2} / \mathrm{Vs}$ under a bending radius of $11 \mathrm{~mm}$.

We further tested the flexible TFTs under lower operating voltages, as shown in Fig. 5. Even under a bias of $0.6 \mathrm{~V}$, well behaved transfer characteristics with an on-current of $1.5 \mu \mathrm{A}$ and a current on/off ratio of $10^{5}$ are achieved. When decreasing to the gate bias to $0.5 \mathrm{~V}$, the maximum drain current is decreased to $0.49 \mu \mathrm{A}$ and the current on/off ratio is decreased to $6 \times 10^{4}$. The carrier mobility is also reduces with gate bias due to carrier trapping by interface states becoming more dominant at lower gate voltages [18].

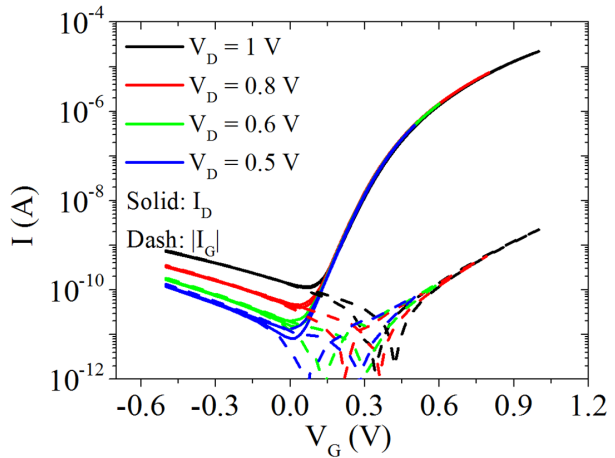

Fig. 5. Transfer characteristics of flexible IGZO TFTs under various $V_{\mathrm{D}}$.

A comparison with previously reported flexible IGZO TFTs is shown in Table I. The electrical properties in terms of operating voltage, mobility, subthreshold swing, threshold voltage shift, and current on/off ratio, $I_{\mathrm{ON}} / \mathrm{I}_{\mathrm{OFF}}$, of our devices match, and even surpass, those of other IGZO TFTs using similar bending conditions.

TABLE I

COMPARISON OF IGZO TFTS ON FLEXIBLE SUBSTRATES

\begin{tabular}{|c|c|c|c|c|c|c|}
\hline Ref. & $\begin{array}{l}\text { Bending } \\
\text { radius } \\
(\mathrm{mm})\end{array}$ & $\begin{array}{l}\text { Operating } \\
\text { voltage (V) }\end{array}$ & $\begin{array}{l}\mu \\
\left(\mathrm{cm}^{2} /\right. \\
\mathrm{Vs})\end{array}$ & $\begin{array}{l}S S \\
(\mathrm{~V} / \mathrm{dec})\end{array}$ & $\begin{array}{l}\Delta V_{\mathrm{TH}} \\
(\mathrm{V})\end{array}$ & $I_{\mathrm{ON}} / I_{\mathrm{OFF}}$ \\
\hline $\begin{array}{l}\text { This } \\
\text { work }\end{array}$ & 11 & 1 & 9 & $<0.09$ & $\begin{array}{l}-0.04 \pm \\
0.01\end{array}$ & $>10^{5}$ \\
\hline [11] & 10 & 10 & 11.2 & 0.27 & I & $>10^{8}$ \\
\hline [19] & 15 & 2 & 76 & 0.15 & I & $>10^{5}$ \\
\hline [20] & 9 & 20 & 3.6 & / & -0.15 & $\sim 10^{4}$ \\
\hline [21] & 10 & 30 & 10.2 & 0.7 & -0.21 & $>10^{7}$ \\
\hline
\end{tabular}

In conclusion, we have reported flexible IGZO TFTs using solution-processed, ultra-thin $\mathrm{Al}_{\mathrm{x}} \mathrm{O}_{\mathrm{y}}$ as the gate dielectric layer. The fabricated devices are capable of operating within $1 \mathrm{~V}$ with a high current on/off ratio $>10^{5}$ and a low subthreshold swing $<90 \mathrm{mV} / \mathrm{dec}$. The devices maintain their high performance even when flexed to a curvature radius of $11 \mathrm{~mm}$. Therefore, this work may have important implications for future low-cost, large-area electronics where a low operating voltage and mechanical flexibility are necessary.

\section{REFERENCE}

[1] K. Nomura, H. Ohta, A. Takagi, T. Kamiya, M. Hirano, and H. Hosono, "Room-temperature fabrication of transparent flexible thin-film transistors using amorphous oxide semiconductors," nature, vol. 432, pp. 488-492, Nov. 2004. DOI: 10.1038/nature 03090

[2] G. D. Wilk, R. M. Wallace, and J. Anthony, "High-к gate dielectrics: Current status and materials properties considerations," J. App. Phys., vol. 89, pp. 5243-5275, May. 2001. DOI: 10.1063/1.1361065

[3] E. Carlos, R. Branquinho, A. Kiazadeh, P. Barquinha, R. Martins, and E. Fortunato, "UV-Mediated Photochemical Treatment for Low-Temperature Oxide-Based Thin-Film Transistors," ACS appl materi interfaces, vol. 8, pp. 31100-31108, Oct. 2016. DOI: 10.1021/acsami.6b06321

[4] Y. Shao, X. Xiao, X. He, W. Deng, and S. Zhang, "Low-voltage aInGaZnO thin-film transistors with anodized thin $\mathrm{HfO}_{2}$ gate dielectric," IEEE Electron Device Lett., vol. 36, pp. 573-575, Apr. 2015. DOI: 10.1109/LED.2015.2422895

[5] C. Chiu, S. Chang, and S. Chang, "High-Performance a-IGZO Thin-Film Transistor Using $\mathrm{Ta}_{2} \mathrm{O}_{5}$ Gate Dielectric," IEEE Electron Device Lett., vol. 31, pp. 1245-1247, Sep. 2010. DOI: 10.1109/LED.2010.2066951 
[6] X.-H. Zhang, B. Domercq, X. Wang, S. Yoo, T. Kondo, Z. L. Wang, and B. Kippelen, "High-performance pentacene field-effect transistors using $\mathrm{Al}_{2} \mathrm{O}_{3}$ gate dielectrics prepared by atomic layer deposition (ALD)," Org. Electron., vol. 8, pp. 718-726, Dec. 2007. DOI: 10.1016/j.orgel.2007.06.009

[7] M. Lohrengel, "Thin anodic oxide layers on aluminium and other valve metals: high field regime," Mater. Sci. Eng. R Rep., vol. 11, pp. 243-294, Dec. 1993. DOI: 10.1016/0927-796X(93)90005-N

[8] M.-J. Jeng and J.-G. Hwu, "Thin-gate oxides prepared by pure water anodization followed by rapid thermal densification," IEEE Electron Device Lett., vol. 17, pp. 575-577, Dec. 1996. DOI: $10.1109 / 55.545775$

[9] W. Cai, S. Park, J. Zhang, J. Wilson, Y. Li, Q. Xin, L. Majewski, and A. Song, "One-Volt IGZO Thin-Film Transistors with UltraThin, Solution-Processed $\mathrm{Al}_{\mathrm{x}} \mathrm{O}_{\mathrm{y}}$ Gate Dielectric," IEEE Electron Device Lett., Mar. 2018. DOI: 10.1109/LED.2018.2798061

[10] H. Xu, D. Luo, M. Li, M. Xu, J. Zou, H. Tao, L. Lan, L. Wang, J. Peng, and Y. Cao, "A flexible AMOLED display on the PEN substrate driven by oxide thin-film transistors using anodized aluminium oxide as dielectric," J. Mater. Chem. C, vol. 2, pp. 1255-1259, 2014. DOI: 10.1039/C3TC31710B

[11] H. Xu, J. Pang, M. Xu, M. Li, Y. Guo, Z. Chen, L. Wang, J. Zou, H. Tao, and L. Wang, "Fabrication of flexible amorphous indiumgallium-zinc-oxide thin-film transistors by a chemical vapor deposition-free process on polyethylene napthalate," ECS J. Solid State Sci. Technol., vol. 3, pp. Q3035-Q3039, Jul. 2014. DOI: $10.1149 / 2.007409$ jss

[12] V. V. Zhirnov and R. K. Cavin, "Nanoelectronics: Negative capacitance to the rescue?," Nat.nanotech., vol. 3, pp. 77-78, 2008. DOI: $10.1038 /$ nnano.2008.18

[13] S. Junfei, D. Chengyuan, D. Wenjun, W. Jie, C. Yuting, and Z. Runze, "The influence of RF power on the electrical properties of sputtered amorphous $\mathrm{In}-\mathrm{Ga}-\mathrm{Zn}-\mathrm{O}$ thin films and devices," J.of Semicond., vol. 34, p. 084003, Aug. 2013. DOI: 10.1088/16744926/34/8/084003

[14] X. Ding, J. Zhang, J. Li, H. Zhang, W. Shi, X. Jiang, and Z. Zhang, "Influence of the InGaZnO channel layer thickness on the performance of thin film transistors," Superlattices Microstruct., vol. 63, pp. 70-78, Nov. 2013. DOI: 10.1016/j.spmi.2013.08.017

[15] S.-H. Choi, J.-H. Jang, J.-J. Kim, and M.-K. Han, "Lowtemperature organic (CYTOP) passivation for improvement of electric characteristics and reliability in IGZO TFTs," IEEE Electron Device Lett, vol. 33, pp. 381-383, Mar. 2012. DOI: 10.1109/LED.2011.2178112

[16] S.-H. Choi and M.-K. Han, "Effect of deposition temperature of $\mathrm{SiO}_{\mathrm{x}}$ passivation layer on the electrical performance of a-IGZO TFTs," IEEE Electron Device Lett., vol. 33, pp. 396-398, Feb. 2012. DOI: 10.1109/LED.2011.2181320

[17] N. Munzenrieder, K. H. Cherenack, and G. Troster, "The effects of mechanical bending and illumination on the performance of flexible IGZO TFTs," IEEE Trans. on Electron Devices, vol. 58, pp. 2041-2048, May. 2011. DOI: 10.1109/TED.2011.2143416

[18] P. Ma, L. Du, Y. Wang, R. Jiang, Q. Xin, Y. Li, and A. Song, "Low voltage operation of IGZO thin film transistors enabled by ultrathin $\mathrm{Al}_{2} \mathrm{O}_{3}$ gate dielectric," Appl. Phys. Lett., vol. 112, p. 023501, Jan. 2018. DOI: 10.1063/1.5003662

[19] H.-H. Hsu, C.-Y. Chang, and C.-H. Cheng, "A Flexible IGZO Thin-Film Transistor With Stacked $\mathrm{TiO}_{2}$ Dielectrics Fabricated at Room Temperature," IEEE Electron Device Lett., vol. 34, pp. 768770, May. 2013. DOI: 10.1109/LED.2013.2258455

[20] D. Kim, B. Hwang, J. Park, H. Jeon, B. Bae, H. Lee, and N.-E. Lee, "Mechanical bending of flexible complementary inverters based on organic and oxide thin film transistors," Org. Electron., vol. 13, pp. 2401-2405, Nov. 2012. DOI: 10.1016/j.orgel.2012.06.038

[21] C.-Y. Lin, C.-W. Chien, C.-C. Wu, Y.-H. Yeh, C.-C. Cheng, C.-M. Lai, M.-J. Yu, C.-M. Leu, and T.-M. Lee, "Effects of mechanical strains on the characteristics of top-gate staggered a-IGZO thinfilm transistors fabricated on polyimide-based nanocomposite substrates," IEEE Trans. on Electron Devices, vol. 59, pp. 19561962, May. 2012. DOI: 10.1109/TED.2012.2193585 